\title{
PROPUESTA DE UN PLAN DE NEGOCIO ENFOCADO EN EL AUMENTO DE VALOR DE UN ENSAMBLE DE JAZZ EN COSTA RICA
}

\section{RESUMEN}

Este trabajo pretende ser una adaptación del instrumental clásico de la administración de negocios aplicado a un bien cultural: un ensamble musical dejazzen Costa Rica. Además de contextualizar la incipiente escena del jazz en el país, se hizo un estudio exploratorio de un fragmento de la oferta y demanda del mercado de la música en vivo: recintos, consumidores y competidores. Se evidencia que al articular las herramientas clásicas de un proyecto de emprendimiento en productos o servicios de naturaleza tan distinta como los son los bienes y servicios culturales, puede mejorar la proyección de sostenibilidad económica de estos sin detrimento del componente creativo y artístico que caracteriza al sector, poniendo en valor la importancia de una adecuada gestión cultural.

PALABRAS CLAVE: JAZZ, COSTA RICA, BIENES CULTURALES, VALOR, EVALUACIÓN FINANCIERA, PROYECTOS, GESTIÓN CULTURAL

\section{ABSTRACT}

This paper intends to be an adaptation of the classical business management tools applying to a cultural good, in this case, a jazzensemble in Costa Rica. Besides of contextualize theemerging
MARIELA PÉREZ SALAZAR

Universidad Carlos III, España marielaperezsalazar@gmail.com music scene in Costa Rica, it was made an exploratory study of a piece of the supply and demand of the live music market: venues, audience, competitors. The evidence shows how the application of the classical tools of an entrepreneurship project in products or services as different as cultural goods and services, can improve their economic sustainability without affecting the artistic and creative component, essential in this type of activities, embracing the value of an adequate cultural management.

KEY WORDS: JAZZ, COSTA RICA, CULTURAL GOODS, VALUE, FINANCE PERFORMANCE, PROJECTS, CULTURAL MANAGEMENT.

\section{PRESENTACIÓN}

El $1^{\circ}$ de Mayo de 1973, José Figueres Ferrer desde la silla presidencial, emitía un discurso memorable en el que planteó “Para qué tractores sin violines?". Hacía una reflexión sobre un hecho que con el tiempo se ha revelado incuestionable: es necesario pensar no solo en el nivel de vida, sino en la clase de vida (Figueres, citado por Sáenz, 2012, p. 19). La educación y la cultura son factores fundamentales para mantener altos niveles de calidad de vida y de igual forma son el mejor mecanismo 
para lograr disminuir muchos de los problemas sociales que aquejan a los países y ciudades en todo el mundo.

La UNESCO, en la Asamblea General número 66 de las Naciones Unidas, efectuada el 26 de julio del 2011 sobre los temas de cultura y desarrollo, plantea que, al realizar una aproximación antropocéntrica de desarrollo, la ampliación del paradigma ha allanado gradualmente el camino para reconocer el rol indispensable que tiene la cultura en el desarrollo sostenible. También, destaca su aporte contributivo en creación de puestos de trabajo y la generación de beneficios económicos (UNESCO, 2011, p. 3).

Si bien en Costa Rica existe cierto grado de conciencia al respecto, el desarrollo de proyectos que nacen desde el arte y la cultura suelen ser muy difíciles de emprender. Esto no solo por el desconocimiento del público en general, sino debido a la falta de conocimiento en la gestión cultural y de recursos económicos que permitan desarrollar estos proyectos.

La música no es la excepción. El último intento gubernamental por trabajar e invertir en la música de forma directa fue en los setenta, gracias al empeño de José Figueres y Guido Sáenz por crear una Orquesta Sinfónica de primer nivel. A partir de ahí, los esfuerzos han sido diluidos. Lo anterior se evidencia principalmente en la falta de escuelas o estudios de otros géneros musicales que permitan profesionalizar al gremio dentro de Costa Rica. A nivel universitario, tanto la Universidad de Costa Rica como la Universidad Nacional se han enfocado en música clásica y en música popular. Por tanto, nichos de otros géneros musicales o están en etapas muy incipientes de desarrollo o dependen de iniciativas aisladas. Vale destacar, por su lado la reciente apertura de la carrera en Gestión Cultural en la Sede del Pacífico de la Universidad de Costa Rica.

Lo anterior, en cierta forma, resume varios vacíos que se pueden notar en Costa Rica. El Estado, si bien ha ido fortaleciendo el Ministerio de Cultura ${ }^{1}$, se ha enfocado en la reactivación de espacios a nivel popular (por ejemplo: Transitarte, Enamórate de tu ciudad, Festival Internacional de las Artes, la Feria Internacional del Libro). Por tanto, existe una precarización laboral generalizada en el sector cultura. A nivel de disciplinas, hay pocas fuentes de apoyo directas para el desarrollo de proyectos y de los mismos artistas. Surgen acciones aisladas y en sí el mercado es sumamente reducido y focalizado. La proyección se da gracias a iniciativas por parte de los implicados, por becas provenientes del exterior o iniciativas de ONGs que tienen como misión fomentar el arte y la cultura.

Como forma de representación artística, la música es un producto cultural con matices y alcances muy diversos. Por un lado, está el factor de mercado-industria, la parte relacionada directamente con el sistema económico de un país y el marco de la industria global de la música y el entretenimiento: sellos disqueros, productoras de conciertos y festivales, salas de ensayo, estudios de grabación, tiendas de instrumentos, escuelas de música, etc. Por otro lado, hay un desarrollo académico-intelectual que no es precisamente el lado lucrativo de este arte, sino más bien el que nace del impulso creativo del artista. Ahí se pueden encontrar estudios musicales de cierta época, desarrollo de virtuosismo y capacidades técnicas, composición, interpretación y demás capacidades desarrolladas en el tiempo por los músicos, tanto de academia como empíricos. Dichos estudios devengan en proyectos que, sin tener como motivación principal un fin lucrativo, se pueden convertir en servicios o productos de alto consumo. Con esto no se hace referencia

1. Cabe hacer el reconocimiento al Ministerio de Cultura por el proyecto de la Cuenta Satélite de Cultura de Costa Rica (http://cuentasatelitecultura.go.cr/) la cual estoy segura, será una fuente muy importante de información y un catalizador importante de trabajos de investigación y generación de proyectos en esta área del desarrollo humano. 
únicamente al consumo de la cultura pop o de masas, sino también a los nichos de personas que ven la música como bien y producto cultural basados en la generación de experiencias y disfrute de la misma.

Volviendo a la frase catalizadora de esta investigación ¿Para qué tractores sin violines? La música, aparte de su valor cultural intrínseco, puede ser un medio de movilización social y una forma de educar y sensibilizar a la población Por tanto, democratizar este tipo de iniciativas contribuiría con el desarrollo integral que propone la UNESCO tanto para el artista como para la sociedad en general.

\section{BREVE RESEÑA DE LA HISTORIA DEL JAZZ Y SU DESARROLLO EN COSTA RICA}

El jazz, desde su creación, ha sido uno de los géneros musicales más influyentes del siglo XXI. Scofield (2007, p. 10) menciona:

...creo que todo el mundo está de acuerdo en que el jazz es uno de los estilos musicales más influyentes, perdurables y definitivos del siglo XX. Sin él, no existiría la música popular tal y como la conocemos [...] El jazz hace una reconocible y significativa contribución a la cultura de todo el mundo.

Sus orígenes se remontan a la época en la que aún existía la escalvitud en los Estados Unidos. Nueva Orleans, una de las ciudades más ricas y cosmopolitas del Siglo XIX, fue la "sociedad integradora donde las melodías caribeñas empezaron a mezclarse con los ritmos africanos traídos por los esclavos y con la melodías clásicas occidentales traídas por los criollos" (Rolf, 2007, p. 16). Desde esta época, el jazz ha pasado por distintas etapas de evolución: el swing; sonidos más urbanos característicos de los años cincuentas; experimentos y fusiones durante los sesentas y setentas; hasta el jazz moderno o música del mundo (word music). También, se pueden mencionar las big bands de la era del swing o los quintetos de bebop, dixieland o vanguardia: "la música vibra con un espíritu colectivo de interactividad y de retos tomados en el preciso instante por los participantes, de modo individual y colectivo" (Rolf, 2007, p. 14) .

Este factor es de suma importancia, ya que para el jazz, el desarrollo técnico del músico así como el desarrollo de su creatividad es vital; primero, para la ejecución y, segundo, para la improvisación, el ingrediente diferenciador de este género. Nunca una interpretación de una pieza es igual a la otra, lo que hace cada presentación única e irrepetible.

Conforme fue evolucionando el jazz, su epicentro de creación se fue extendiendo por todo el mundo. Con ello, y gracias a su evolución constante, fue incorporando influencias de otros géneros y realidades culturales distintas. A su vez, fue influenciando a otros géneros en todo el mundo, los cuales añadieron libertades y sonidos que ofrecía este género. Por tanto, se convierte en "una parte integrante del siempre cambiante panorama musical del mundo moderno" (Rolf, 2007, p. 12).

Costa Rica no fue la excepción. En una entrevista realizada a Luis Monge, pianista y compositor, pionero en el género jazz en Costa Rica (Núñez, 2009), cuenta que antes de los años setenta no existió contacto con el jazz. Monge menciona que los principales factores fueron: "la ubicación geográfica, la poca importancia que se le otorgaba a algunos estilos musicales en los altos círculos culturales y la falta de lugares en los que se interpretaban repertorios como el jazz" (citado por Núñez, 2009, p. 2). Si bien anterior a este período algunas bandas incorporaron repertorios de jazz, principalmente de las big bands, fue hasta los setenta cuando los músicos se empezaron a interesar de forma profesional en el género. 
La mayoría de estos músicos cursaron carreras profesionales fuera de Costa Rica, en Estados Unidos y Europa principalmente. Destacan Luis Monge, Vernon "El Pibe" Hine y José "Chepe" González. Este fue un factor contundente en la incorporación del jazz a la escena costarricense. El guitarrista Edgar Sequeira, graduado de Florida International University (F.I.U), menciona que esta generación (refiriéndose a los músicos que tocan actualmente jazz) es aproximadamente la tercera de músicos que tocan jazz y han buscado un desarrollo profesional en el género (Sequeira, 2015). Además, Sequeira destaca que espacios como El Sótano, club de jazz por excelencia de San José, que opera regularmente desde el 2012, ha sido vital para el desarrollo de la escena y la evolución del lenguaje y nivel de los músicos costarricenses. Esto por su programación constante de jazz nacional e internacional, por ser un espacio semanal para jam sessions ${ }^{2}$ y por la dinámica que genera entre el círculo, como el vínculo que tiene con artistas internacionales que han pasado por su escenario.

Otro catalizador de la incorporación del jazz en Costa Rica fue la llegada de los "tocadiscos" o "tornamesas" y la tecnología de los discos de acetato, ya que permitieron que la música pudiera viajar y no solo se pudiera escuchar en cuerpo presente gracias a los conciertos y presentaciones en vivo. Cabe destacar que, desde los inicios y dado que es imposible sacar al músico de su contexto socio-cultural, el jazz en Costa Rica ha tenido influencias latinas. Núñez (2009) menciona que Luis Monge distinguió la diferencia estando en Alemania donde se percibió una expresión distinta del jazz con influencias latinoamericanas por parte de sus colegas europeos y norteamericanos.

2. Jam Session es una reunión de músicos que no suelen trabajar juntos y que improvisan a partir de temas conocidos por todos (Cifuentes, 1995).
Suma, de igual forma, el hecho de que cada vez es más fácil observar en escenarios costarricenses artistas de talla internacional con proyectos muy pontentes de jazz que se escuchan a nivel internacional, tanto para el músico como para el público de este tipo de actividades lo que permite ir creando y consolidando una comunidad en torno al género. Entonces, si bien el jazz es un género relativamente nuevo en Costa Rica, el desarrollo ha sido exponencial. En los setenta era inconcebible pensar la cantidad de proyectos de alto nivel que se encuentran activos actualmente y que, además, cuenten hoy con repertorios y producciones de música original.

\section{INTRODUCCIÓN}

El nuevo panorama de la incipiente industria musical y, en particular en la escena del jazz en Costa Rica, aunado al cambio tecnólogico tanto a nivel de softwares para producción musical como el internet, han ido transformando poco a poco las dinámicas de este sector. Por ejemplo, ACAM, un organismo no gubernamental (ONG) "que vela porque en Costa Rica se apliquen y respeten los niveles jurídicos de protección vigentes respecto al uso de las obras musicales pertenecientes a sus asociados y a los creadores de música" (ACAM Costa Rica, 2012) pasó de tener 25 miembros en 1990 a más de 2000 miembros actualmente.

Si bien, y como se mencionó anteriormente, los vacíos existen en muchas áreas tanto en la esfera pública como privada, han surgido propuestas fuera de las instancias oficiales, que han abierto nuevos nichos de mercado y se están empezado a dar a conocer en un público creciente y adepto. Esto permite la visualización de proyectos como opciones rentables o inclusive como proyectos de emprendimiento más formales.

Hoy, la escena del jazz costarricense se conforma por un grupo de aproximadamente 55 músicos y se podría hablar de unos nueve proyectos de alto nivel que se encontraban activos al momento de 
realizar el trabajo de campo de esta investigación. Cabe mencionar que muchos de los músicos participaban en varios proyectos a la vez, o pluriempleo, propio del sector laboral en cultura.

Además, durante el trabajo de campo se evidenció que existen pocos lugares para tocar de forma regular. Únicamente existen tres recintos para escuchar jazz y están ubicados en San José. A esto se le suma que algunos restaurantes han incorporado a su servicio música en vivo de este género, más los eventos de empresas o sociales que funcionan como fuentes de ingreso para este tipo de ensambles.

Dado que actualmente no existe un intento de formalización empresarial de dichos proyectos de emprendimiento, este trabajo intenta marcar un precedente de herramienta de análisis y evaluación en el área de la administración de negocios enfocada a la gestión cultural que responda a las necesidades y características de proyectos musicales que se encuentran en marcha o proyectos en etapa de desarrollo. Además, dado que la falta de recursos económicos y la aparente ausencia de rentabilidad de proyectos como este se convierten en la principal limitante de emprendimiento surge la idea de esta investigación.

Para ello, el objetivo general es elaborar una metodología de evaluación que sea la base de una propuesta de plan de negocio que permita el incremento del valor de un ensamble de jazz en Costa Rica. Para ello, se estudió la situación actual del mercado para categorizar la demanda potencial y los competidores actuales. Se crearon productos derivados del ensamble para el desarrollo de estrategias de penetración y precios que faciliten la introducción del producto. Se plantea una estrategia de branding y comunicación que fortalezca y diferencie la marca. Para evaluar desde el punto de vista financiero, el plan de negocios propuesto, se establecieron escenarios hipotéticos con sus respectivos flujos de caja e indica- dores para cuantificar la propuesta y extraer las conclusiones del caso.

\section{SOBRE EL ALCANCE Y LAS LIMITACIONES}

El alcance y las limitaciones de esta investigación se debieron, principalmente, a un tema de recursos económicos y tiempo, ya que todo el trabajo de campo se realizó por la investigadora y fue la base de su Trabajo de Fin de Máster entregado en Noviembre de 2015 . La demanda potencial se definió como los lugares públicos, tales como bares y restaurantes donde un ensamble de jazz podría tocar regularmente. Quedaron excluidos otros mercados como bodas, eventos especiales, hoteles, centros comerciales, entre otros. De igual forma, el estudio se enfoca en identificar a los competidores activos y descarta a los que están enfocados en otros mercados.

Se delimitó geográficamente a los focos de San José que forman parte de la Gran Área Metropolitana ${ }^{3}$ (GAM), donde se ha concentrado la movida nocturna. La identificación de los focos no se realizó estrictamente por cantón (podría haber varios focos en un mismo cantón), sino que se identificaron conglomerados donde se ha instituido una movida nocturna. Se espera que este trabajo funcione como una aproximación inicial que permita a otros proyectos musicales encontrar herramientas base que les permitan mejorar la rentabilidad y, a la vez, sirva de precedente para democratizar el acceso y disfrute del público en general de este tipo de iniciativas musicales.

3. El área metropolitana de San José la conforman los cantones de: San José, Escazú, Goicochea, Santa Ana, Alajuelita, Tibás, Moravia, Montes de Oca y Curridabat. Desamparados, Aserrí, Mora y Vázquez de Coronado de forma parcial. (OUGAM, 2014). 


\section{METODOLOGÍA}

Este estudio se desarrolló a luz de un paradigma mixto de investigación, asignándole un peso mayor al paradigma cualitativo por llevar a cabo un proceso inductivo que no pretendió generalizar los datos y por basarse en métodos de recolección no estandarizados (Hernández, Fernández \& Baptista, 2006). Además, cabe mencionar que, según González (2012), esta investigación contiene un matiz socio-crítico, ya que se utilizaron las herramientas clásicas de la administración de negocios planteadas para proyectos que en principio no tienen como fin el lucro. Más bien, parten de impulsos artísticos y curiosidad intelectual en el marco de las manifestaciones artísticas, creativas y culturales cuyos cimientos no son proyectos de emprendimiento que procuren la sostenibilidad económica.

El alcance de esta investigación tiene características del tipo exploratorio, al ser una aplicación poco estudiada conforme a los objetivos planteados, pero es del tipo descriptiva. Según Hernández, Fernández y Baptista (2006), una investigación descriptiva considera a un fenómeno y sus componentes, mide conceptos y define variables. Además los estudios del tipo descriptivo buscan especificar las propiedades, características y perfiles importantes del fenómeno que se someta a análisis. Este estudio posee, principalmente, variables cualitativas; sin embargo, las variables cuantitativas fueron las que dieron luz sobre el resultado de viabilidad económica y financiera que arroja el plan de negocios.

\section{INSTRUMENTOS DE RECOLECCIÓN DE DATOS}

Para este trabajo se utilizaron diversas herramientas y procesos de recolección de datos de fuente primaria. La primera, consistió en una encuesta que permitió recoger información descriptiva sobre las características de las personas que escuchan jazz en vivo, trazando un esbozo del perfil sociodemográfico como: sexo, edad, cantón de residencia, grado académico o nivel de escolaridad, la tenencia o no de vehículo, la profesión y por último el nivel de ingreso.

El otro objetivo de esta encuesta fue arrojar luces sobre los gustos y preferencias de esta fuente primaria. Los resultados obtenidos permitieron identificar el grado de inclinación por la música, la disposición de pago por un tipo de eventos que involucren el jazz, el interés por el jazz propiamente, la frecuencia con la que asiste a dichos eventos, los días de la semana de preferencia para asistir y los lugares (tanto a nivel geográfico como de tipos de establecimiento) de preferencia para escuchar este género.

La segunda herramienta que se utilizó para la recolección de datos fue el uso de una bitácora de la se derivó una base de datos. Con ella, se generó una caracterización del perfil de establecimientos que podrían actuar como demandantes potenciales de un ensamble de jazz, tomando como unidad de análisis los bares, cafeterías y restaurantes. Dicha bitácora consistió en un diario escrito a mano donde se anotaron las características físicas a nivel externo (ubicación, servicio de parqueo) como interno (equipamiento de sonido, capacidad de aforo), contacto/encargado y potencial que tienen los lugares visitados (Ilámese bares, restaurantes, cafeterías, etc.). El método se basa en la observación y para este caso se complementó con algunas entrevistas a encargados de los respectivos locales cuando hubo oportunidad.

La tercera herramienta fueron entrevistas a profundidad. Para la sección de estrategia de branding y diseño de la imagen, se dialogó y trabajó con un profesional en diseño, ilustración y comunicación. También, se realizaron entrevistas en profundidad a músicos activos en la escena del jazz en Costa Rica, con el fin de identificar aspectos clave a la hora de diseñar los productos derivados de un en- 
samble y una base de repertorio entorno a estándares ${ }^{4}$ de jazz.

La última herramienta utilizada fue la estrategia de cliente incógnito para la caracterización de los competidores directos. Se manejó a través de correo electrónico y mediante el uso de las plataformas web y redes sociales de cada competidor identificado, con el fin de obtener información verídica, principalmente sobre la variable precios, tipos de ensambles ofertados, repertorio o géneros musicales interpretados. En paralelo, se llevaron anotaciones sobre las herramientas de comunicación que se identificaron a la hora de analizar cada competidor.

\section{RECOLECCIÓN DE LA INFORMACIÓN/ TRABAJO DE CAMPO}

Por el tipo de investigación, una gran parte del tiempo se destinó a la recolección de información primaria. Las encuestas se aplicaron entre los meses de febrero y abril de 2015. Se seleccionaron cinco fechas donde hubiese eventos de diferente índole de jazz. Se elegió el recinto El Sótano por ser el único con una programación semanal de dicho género, desde Jam Sessions (sesiones de improvisación) hasta conciertos con músicos internacionales de alto calibre. Si bien podría existir un sesgo al solo aplicar las encuestas en un lugar físico, este no sería muy significativo debido a lo pequeña que es la movida del Jazz en Costa Rica y al ser El Sótano el foco principal de este género. Además, por el límite en los recursos económicos y de capital humano de esta investigación, no fue posible aplicar las encuestas en otros lugares donde se realicen, ya sea de forma aislada o de forma regular, dichas actividades

Para el mapeo de recintos que podrían actuar como demandantes potenciales de un ensam-

4. Un estándar de jazz (jazz standars) es "una canción que ha conseguido resistir la prueba del tiempo y que permanece en los repertorios de sucesivas generaciones de músicos"son claves en el lenguaje musical de la escena jazzística a nivel mundial (Cifuentes, 1995). ble de estas características, se limitó geográficamente a los cantones de la provincia de San José, provenientes de la GAM: San José, Escazú, Goicochea, Santa Ana, Alajuelita, Tibás, Moravia, Montes de Oca y Curridabat. De forma parcial se incluyen Desamparados, Aserrí, Mora y Vázquez de Coronado. No se tomaron en cuenta los cantones que son parte de forma segmentada a la GAM.

Definidos estos sectores, se identificaron las zonas donde hay concentración de vida nocturna. Con ello, se hace referencia a zonas donde existan activos como mínimo tres lugares con ambiente nocturno. La definición de la zona geográfica se asigna según densidad o concentración de bares-restaurantes y no por dimensión territorial. Se encontraron las siguientes concentraciones de vida nocturna: San José (Centro, Barrio Amón, Barrio Escalante, Barrio la California, Los Yoses, Paseo Colón, La Sabana, Barrio Aranjuez), San Pedro, Pavas-Rohrmoser, Escazú (San Rafael, Lindora, Santa Ana, Guachipelín; es decir, Zonas aledañas a Multiplaza Escazú), Curridabat-Zapote y, por último, Tibás-Moravia.

Establecidos los límites geográficos, se procedió a visitar los lugares que se encontraban abiertos entre las 17:00 y las 2:00 horas. Estas se realizaron entre enero y mayo del 2015, y generaron un total de 208 registros. Resultaron importantes los centros comerciales, punto de ocio relevante en la vida de los costarricenses y puntualizando los lugares que al momento de realizar la investigación ya ofrecían dentro de sus servicios la presencia de música en vivo de estas características.

Respecto a las observaciones anotadas, destacan los aspectos como atributos físicos (internos y externos), equipamiento de sonido/amplificación (si aplica), servicios adicionales, capacidad de aforo, ambiente y público meta. En algunos casos se habló directamente con el administrador o encargado, lo que permitió averiguar si había disponibilidad de pago (presupuesto) para contratación de grupos de música. 
Para poder identificar los proyectos de jazz, además de realizar el método del cliente incógnito, se habló directamente con músicos que forman parte de los ensambles haciendo principal acento en conocer el número de miembros, instrumentación, precios, repertorio y lugares donde se presentaban de forma regular.

\section{Dimensiones del estudio}

\section{CARACTERIZACIÓN DE LA DEMANDA POTENCIAL Y COMPETIDORES ACTUALES}

La demanda se definió en dos partes: los bares-restaurantes-cafeterías como contratantes del servicio de forma directa y, por otro lado, las personas que asisten a eventos de jazz en vivo. Considerarlos de esta forma, permiten abarcary definir las demandas potenciales según las dos formas principales en las que se llevan a cabo estos eventos: uno es por contratación directa del local como servicio adicional a su clientela y el otro conocido como "por puerta", en el cual se le cobra a cada asistente un precio por el concierto y la banda obtiene como ingreso lo generado por la taquilla. Dado que cada local puede preferir una u otra opción, fue necesario dividir ambos segmentos de la demanda.

Para el caso de los establecimientos, se eligieron como indicadores factores que pueden resultar determinantes a la hora de considerar la compatibilidad del servicio. Si bien la mayoría las observaciones es descriptiva, se plasmó el criterio del investigador para el caso de observaciones más subjetivas; puntualmente, el ambiente y público meta que se percibió sobre el recinto. Por otro lado, la demanda representada por las personas que asisten a presentaciones de jazz en vivo se caracterizó mediante la información que proporcionaron los datos de la encuesta. Con esta información, se procuró encontrar los puntos de convergencia entre ambos sectores de la demanda para poder aterrizar de forma más concreta esa demanda potencial y con ello trasladar la información a datos para lograr la estimación de los flujos de ingreso para los escenarios hipotéticos planteados.

Respecto a la oferta, como lo determina la teoría de mercadeo (Torreblanca, 2014) existen competidores directos e indirectos. Los competidores directos son "aquellos que ofrecen al mercado al que nos dirigimos un producto o servicio con las mismas características que el nuestro" y, siguiendo a Torreblanca (2014), los competidores indirectos son "todos aquellos que intervienen de forma lateral en el enfoque de mercado que tenemos planteado con nuestro producto o servicio". Esta investigación identificó únicamente a los competidores directos para esbozar la oferta de mercado que existía de ensambles de jazz activos al momento de la investigación, siendo agrupaciones instrumentales o con repertorio vocal en el género del jazz y derivados con otros géneros de la música, fusión y/o arreglos. Agrupaciones que interpreten otros géneros o covers ${ }^{5}$ no fueron tomadas en cuenta.

\section{DEFINICIÓN DEL ENSAMBLE}

Se considera un ensamble a un conjunto de músicos que varían en número e instrumentación. Existen dúos, tríos, cuartetos, quintetos, hasta llegar a ensambles como las Big Bands que pueden estar conformadas hasta por más de veinte músicos.

Para este caso se optó por tener un quinteto que incorpore batería y contrabajo, en su base rítmica; guitarra y dos instrumentos de viento: una combinación entre saxofones y trompetas.

5. La palabra cover viene del inglés y significa cubrir. En música, se utiliza para referirse a los casos en que un grupo de músicos interpreta una canción tal y como fue escrita y grabada, sin ningún tipo de modificación o arreglo que la diferencia de la pieza original. 
Esta conformación se eligió en función de lo más característico de los proyectos de jazz y la instrumentación que requiere usualmente el repertorio de estándares de jazz. Además, partir de una base con estas características permite generar una serie de productos derivados en formatos más pequeños, que propicien adaptarse a las distintas condiciones de demanda sin detrimento de la parte musical.

\section{IMAGEN, ESTRATEGIA DE BRANDING Y COMUNICACIÓN}

Resultan vitales al momento de plantear un proyecto como este, no solo los aspectos de calidad en torno a la parte artística: nivel de los músicos, repertorio, capacidad interpretativa, improvisación, diálogo entre músicos; sino también es relevante puntualizar los factores de identidad y diferenciación en el plano de marca y empresa. Respecto a la imagen y el diseño gráfico, se deben tomar en cuenta aspectos de identidad visual que reflejen de forma contundente lo ofrecido por el proyecto. Aspectos como color, tipografía, estilos de comunicación en redes sociales, diseño web, logo e imágenes que transmitan el perfil de calidad y proyección cultural como proyecto musical.

Además, en la actualidad resultan indispensables los medios de comunicación digitales. Tener presencia en plataformas como Facebook, Soundcloud, Instagram y un sitio web con la información pertinente y muestras de audio son herramientas vitales a la hora de ofrecer un proyecto, colocarlo y consolidarlo. La elaboración de material impreso como tarjetas de presentación, dossier, afiches, entre otros, puede ser una forma de diferenciarse y una forma de materializar un producto intangible como este.

\section{INTERPRETACIÓN Y ANÁLISIS DE LOS RESULTADOS}

\section{PERFIL DE LOS ENCUESTADOS}

En total, se encuestaron 53 personas. Las encuestas se llevaron a cabo personalmente por la investigadora. Interesa destacar que el aforo a este tipo de eventos ronda las veinte personas por evento; sin embargo, puede variar considerablemente dependiendo de los músicos y el repertorio que se presente. De igual forma, hay ocasiones en que la taquilla no sobrepasa las diez personas, lo que es coherente también con un género que no es del todo para públicos masivos, de ahí la muestra pequeña.

De las personas encuestadas, el 68\% son hombres, lo que muestra que el jazz tiene un público en su mayoría masculino. Vale mencionar que el 100\% de los músicos que conformaban los ensambles durante las fechas monitoreadas fueron hombres. De hecho, solo uno de los proyectos de jazz que se encontraban activos contaba con una mujer músico en su alineación.

Se realizó un histograma con el fin de identificar el acumulado por edad. Para determinar el número de clases, se utilizó la Regla de Sturges ${ }^{6}$ (Figura 1). El rango de los datos es de 32, siendo de 23 años la persona más joven que llenó la encuesta y de 52 años la de más edad. Con base en lo anterior, la longitud de cada clase quedó de cinco años.

Del histograma, obsérvense principalmente dos elementos: el primero, la distribución de los datos no se comporta como una distribución normal. El segundo, es que el grueso de la población que asiste a estos eventos forma parte del

6. La regla de Sturges plantea que el número de clases viene dado por la función: $C=1+\log _{2} M$

Donde $C=$ número de clases, redondeado al entero más cercano y $\mathrm{M}$ es el tamaño de muestra. 


\section{FIGURA 1 \\ DISTRIBUCIÓN DE FRECUENCIAS DE LOS ASISTENTES A LOS CONCIERTOS DE JAZZ EN EL SÓTANO POR EDADES (FEBRERO-ABRIL, 2015)}

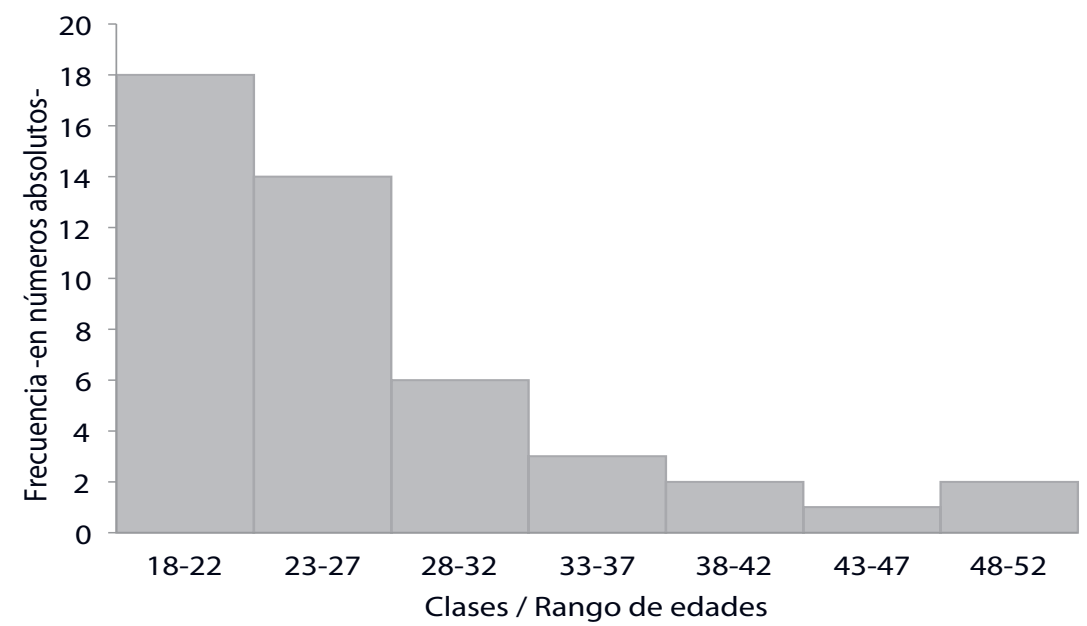

Fuente: elaboración propia

grupo de adultos jóvenes y que en mayoría son menores de 40 años. La moda y el promedio de la edad es igual a 26 años, mientras que la mediana corresponde a los 24 años de edad.

Del total de los encuestados, $61 \%$ viven fuera de San José, pero dentro de la GAM, y solo 40\% posee vehículo propio. La tabla 1 muestra la distribución de los encuestados por provincia según la profesión.

El 49\% de los encuestados son músicos o están estudiando para serlo. Aunado a ello, del 51\% restante, el 28\% de los entrevistados actualmente estudia o tiene como pasatiempo la práctica de algún instrumento. Lo anterior arroja un resultado sumamente contundente, ya que el 79\% de los asistentes a este tipo de eventos están -de una u otra manera- relacionados de forma directa con la música.

Otro factor que se quiso monitorear era la frecuencia con la que las personas entrevistadas asisten a este tipo de eventos. Los resultados se muestran en la Figura 2.

Los datos en este respecto siguen siendo coherentes con lo que se esperaba. La mayoría de las personas que asiste únicamente una vez al mes en su mayoría es de otras áreas profesionales; mientras que, el 100\% de las personas que asisten cinco veces -o más- al mes a este tipo de conciertos son músicos. También, es importante resaltar que un porcentaje pequeño, de 15\%, no asiste de forma regular. Se puede decir que los clientes en su mayoría son regulares y tienden a estar yendo a este tipo de actividades como opción de ocio.

Respecto a los lugares donde los encuestados pusieron el lugar en el que les gustaría que hubiese Jazz en vivo, las categorías más recurrentes fueron:

- Lugares públicos abiertos como parques o plazas públicas. 
TABLA 1

DISTRIBUCIÓN PORCENTUAL DE LOS ASISTENTES A LOS CONCIERTOS DE JAZZ DE EL SÓTANO POR PROVINCIA SEGÚN PROFESIÓN

\begin{tabular}{|c|l|l|l|}
\hline \multirow{2}{*}{$\begin{array}{c}\text { Provincia } \\
\text { San José }\end{array}$} & $\begin{array}{c}\text { Músico, profesor o } \\
\text { estudiante de música }\end{array}$ & Otros & Total \\
\hline Heredia & $21 \%$ & $25 \%$ & $38 \%$ \\
\cline { 2 - 4 } Alajuela & $8 \%$ & $9 \%$ & $30 \%$ \\
\hline Cartago & $4 \%$ & $4 \%$ & $11 \%$ \\
\hline Otros & $4 \%$ & $8 \%$ & $11 \%$ \\
\hline Total & $49 \%$ & $6 \%$ & $9 \%$ \\
\hline
\end{tabular}

Fuente: Elaboración propia

FIGURA 2

\section{ASISTENTES DE CONCIERTOS EN EL SÓTANO. DISTRIBUCIÓN DE LA REGULARIDAD CON LA QUE ASISTEN} A EVENTOS DE JAZZ SEGÚN PROFESIÓN (FEBRERO-ABRIL, 2015)

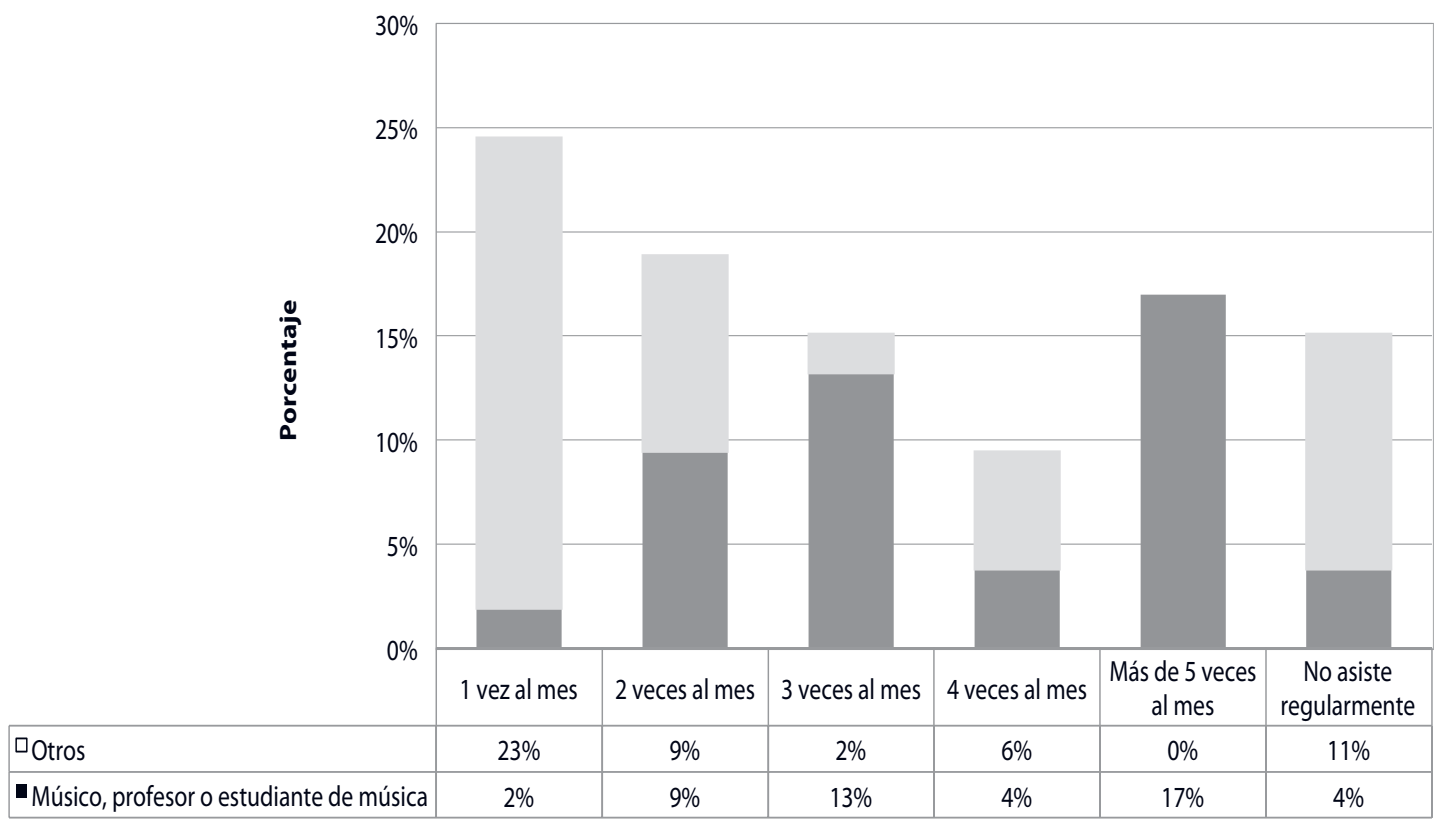

Fuente: elaboración propia. 
- Lugares públicos cerrados como museos, bibliotecas, municipalidades, universidades.

- Lugares privados de interés cultural como teatros o centros culturales.

- Lugares con carácter comercial como bares, restaurantes o cafeterías.

- Centros comerciales.

De las categorías mencionados anteriormente, la que obtiene mayor cantidad de frecuencias son los lugares de carácter comercial como bares, restaurantes y cafeterías, apareciendo en el $51 \%$ de las respuestas, ya fuera de forma explícita (colocando propiamente las palabras: bares, restaurantes y cafeterías) o de forma implícita (mencionando algún nombre propio o refiriéndose a bares de alguna provincia fuera de San
José). El otro rubro importante es el de los lugares públicos abiertos, apareciendo en un 34\% de las encuestas realizadas, lo que muestra que a un importante porcentaje de los encuestados le gustaría que hubiese presencia de esta música en lugares públicos y de acceso gratuito.

Sobre la disponibilidad de pago que tiene un potencial asistente en función de: (1) si el concierto es de una agrupación costarricense, (2) de una banda costarricense con invitado internacional o (3) de una banda internacional, hubo gente que estableció rangos. En estos casos, se tomó como referencia el valor más alto al ser considerado el monto máximo a pagar según cada escenario planteado. Antes de analizar la relación entre la disponibilidad de pago, el nivel de ingreso y la profesión u oficio, se presenta un gráfico que resume la distribución de ingresos de los encuestados (Figura 3).

FiguRA 3

ASISTENTES DE CONCIERTOS DE JAZZ EN EL SÓTANO. DISTRIBUCIÓN POR GRUPO DE INGRESO PROMEDIO MENSUAL SEGÚN PROFESIÓN (FEBRERO-ABRIL, 2015)

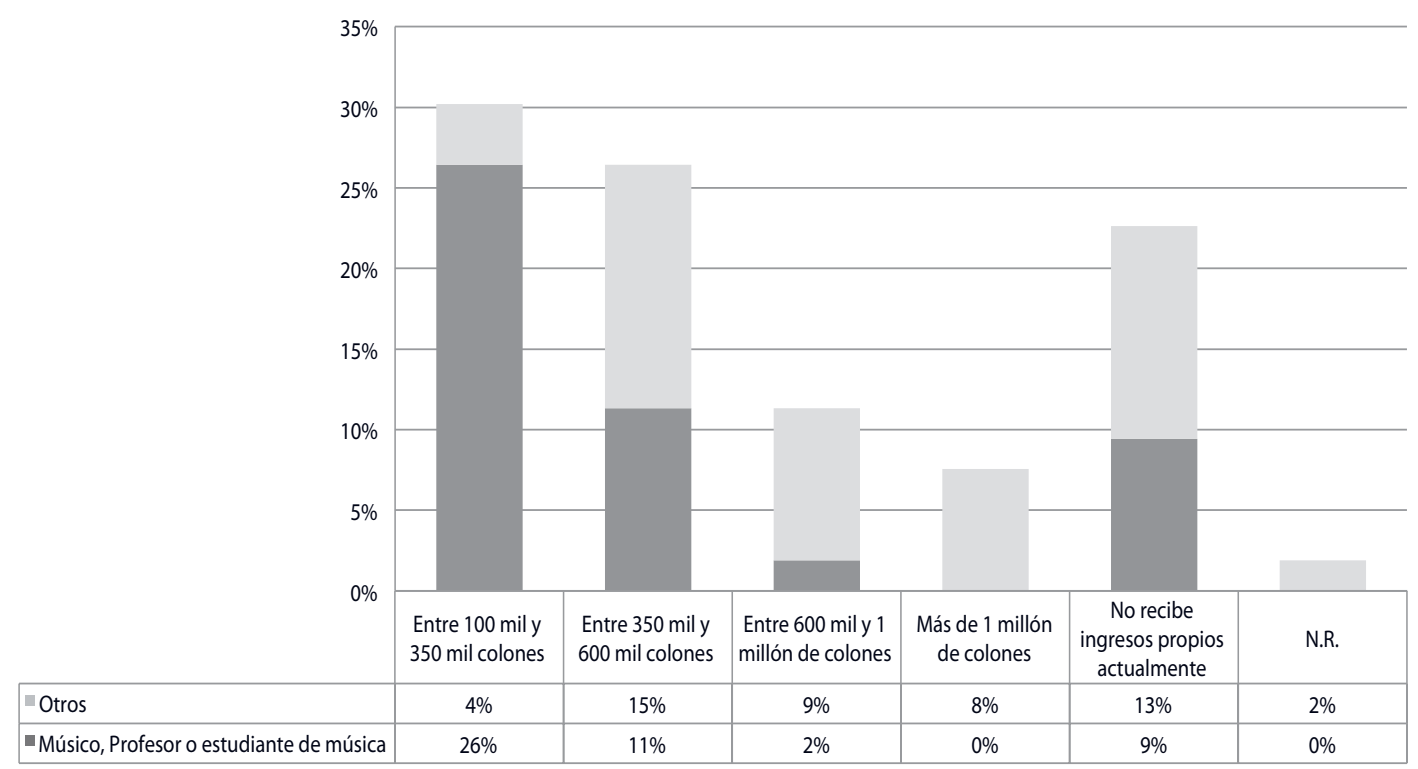

Fuente: elaboración propia. 
De la Figura 3 se destacan dos particularidades. La mayoría de los encuestados que tienen como profesión la música son estudiantes de esta rama o se encuentran en el primer rango de ingreso. La otra particularidad es que ningún encuestado de este grupo gana actualmente más de un millón de colones. Una vez tenido este panorama, se intentó visualizar si existía una relación entre el nivel de ingreso, la profesión y la disponibilidad de pago para cada tipo de evento.

Para ello, de la base de datos original se generó una secundaria con datos donde se dividió primero por profesiones, agrupando de nuevo a los músicos, profesores y estudiantes de música del resto de profesionales. Una vez hecho esto, se agruparon en función de su nivel de ingreso con su correspondiente disponibilidad de pago para cada caso. Realizado este ejercicio, para cada grupo de datos se obtuvieron los indicadores clásicos de la estadística descriptiva: promedio, moda, mediana y desviación estándar. Obtener estos valores permitió observar que los datos eran muy dispersos, aunado a que la muestra es pequeña.

Además, ciertos valores alteraban de forma espuria las funciones de promedio y desviación estándar y en la mayoría de los casos no existía un valor que reflejara la moda en los datos. Debido a ello, se consideró que el valor más apropiado para dar una luz sobre la disponibilidad de pago en función al nivel del ingreso era la mediana, como reflejo del valor medio del precio que las personas están dispuestas a pagar por cada uno de los tipos de conciertos. Los resultados obtenidos se muestran en la tabla 2. Si se observa, una mayor disponibilidad de pago no necesariamente está asociada a un nivel mayor de ingreso.

\section{TABLA 2}

\section{DISPONIBILIDAD DE PAGO EN COLONES DE LOS ASISTENTES A CONCIERTOS DE JAZZ EN EL SÓTANO PARA CADA TIPO DE CONCIERTO SEGÚN SU INGRESO MENSUAL Y ÁREA DE PROFESIÓN}

\begin{tabular}{|c|c|c|c|c|c|c|}
\hline Tipo de concierto & \multicolumn{2}{|c|}{ Banda costarricense } & \multicolumn{2}{|c|}{$\begin{array}{c}\text { Banda costarricense } \\
\text { con invitado interna- } \\
\text { cional }\end{array}$} & \multicolumn{2}{|c|}{ Banda internacional } \\
\hline Ingreso Mensual & Músico* & Otro & Músico & Otro & Músico & Otro \\
\hline Entre 100 mil y 350 mil colones & 5.000 & 14.000 & 7.500 & 17.500 & 10.000 & 25.000 \\
\hline Entre 350 mil y 600 mil colones & 5.000 & 3.000 & 10.000 & 5.000 & 17.500 & 8.000 \\
\hline Entre 600 mil y 1 millón de colones & 4.000 & 5.000 & 5.000 & 1.000 & 30.000 & 10.000 \\
\hline Más de 1 millón de colones** & N.A. & 3.000 & N.A. & 6.000 & N.A. & 10.000 \\
\hline No recibe ingresos propios actualmente & 8.000 & 5.000 & 12.500 & 5.000 & 17.500 & 15.000 \\
\hline Disponibilidad de pago promedio & 5.500 & 6.000 & 8.750 & 6.900 & 18.750 & 13.600 \\
\hline
\end{tabular}

Nota: * La categoría músico en este caso abarca músicos, profesores y estudiantes de música.

**Recordar que no hubo ningún músico entrevistado que tuviese este nivel de ingreso.

Fuente: Elaboración propia 
Sin embargo, el valor más interesante y que servirá de referencia para la creación de escenarios, es la disponibilidad de pago promedio para cada tipo de concierto por profesión. Nótese que únicamente en los conciertos de bandas costarricenses, el precio promedio es 500 colones menos para los músicos que para los profesionales o estudiantes de otras carreras; mientras que, en las otras categorías de conciertos, la disponibilidad de pago de los músicos sí es representativamente mayor. Esta es $27 \%$ y $37.87 \%$ más alta que la de los otros profesionales en los conciertos de bandas nacionales con invitado internacional o en bandas internacionales respectivamente.

Lo anterior es coherente, ya que, por un lado, al ser los músicos los que asisten de forma más regular a este tipo de eventos y al ser en su mayoría una programación de bandas nacionales, la disponibilidad de pago es menor porque el número de proyectos que se encuentran activos es reducido. Por tanto, repiten las presentaciones en los distintos recintos que programan este tipo de actividades con regularidad. En cambio, cuando llega un invitado internacional o una banda extranjera, es de esperarse que la disponibilidad de pago de los músicos aumente de forma considerable y además se separa de la disponibilidad de pago de las personas ajenas a este gremio o que asisten únicamente a este tipo de actividades por pasatiempo y además de forma irregular.

\section{PERFIL DE LOS ESTABLECIMIENTOS}

En total, se visitaron 208 lugares entre bares, restaurantes y cafeterías. En cada visita se anotaron características referentes a atributos físicos (internos y externos), equipamiento a nivel de sonido, disposición de pago o si existía algún presupuesto para música en vivo, capacidad de aforo y aspectos más subjetivos como el ambiente y el público meta. Se categorizaron de la siguiente forma:

a) Lugares donde actualmente hay música en vivo como mínimo una vez por semana, sin importar el género musical: 28 recintos.

b) Lugares donde actualmente hay jazz en vivo de forma regular en cualquier formato, ya sea desde solistas hasta grupos de 4 a 5 personas::11 recintos.

c) Lugares donde no hay música en vivo actualmente, pero mostraron interés en un tipo de servicio como este. En general son restaurantes con ambientes tranquilos y lugares espaciosos: 53 recintos.

d) Lugares donde no hay música en vivo y actualmente no tienen interés en tener este estilo musical o el tipo de lugar no es para el género (de ambiente más de fiesta), debido al público meta o al tipo de actividades que ahí se realizan. También, quedaron en esta categoría los lugares con identidades étnicas muy fuertes que, de solicitar este tipo de servicios, tendrían que ser relacionados con la temática del lugar; por ejemplo, un restaurante de comida japonesa o india: 91 recintos.

e) Lugares que, ya fuera por razones estructurales (muy pequeños, por ejemplo) o que por razones intangibles no cumplen con las características mínimas para albergar un proyecto de esta naturaleza, tampoco se pueden descartar de forma tan evidente como los de la categoría anterior: 25 recintos.

Nótese que apenas un 5.3\% de los 208 locales identificados durante el período en que se realizó el trabajo de campo habían contratado ensambles des de jazz para sus locales. A estos locales se les prestó más atención que al resto, ya que de primera entrada se incluyen como demandantes de este tipo de servicios. Los 
presupuestos de estos lugares iban desde los ¿120 mil a los $\$ 60$ mil por presentación (para un máximo de 4 músicos) o $\$ 45$ mil por músico para el pago más alto y $\$ 15$ mil por músico el precio más bajo, ambos para formato trío.

Además, se identificaron los lugares que funcionan como los actuales recintos para conciertos y música en vivo, en general en San José. Al momento de realizar el trabajo de campo, en Costa Rica no existe propiamente un recinto para realizar conciertos que sea de un aforo pequeño (no conciertos multitudinarios) con las características estructurales apropiadas de una sala de conciertos. De ahí que muchos lugares que iniciaron como bares se han transformado en recintos para conciertos. De los 208 visitados, solamente once pertenecían a esta categoría y solo uno fue realmente diseñado y creado desde su origen para ello.

\section{PERFIL DE LOS COMPETIDORES}

Se identificaron doce proyectos de jazz. De ellos, se descartaron cuatro, por encontrarse inactivos, y dos Big Bands que no se tomaron como competidoras por la diferencia en tamaño y formato. De los ocho restantes, cuatro eran tríos; uno, un cuarteto; uno, que contaba versión cuarteto vocal y un trío instrumental.

Únicamente dos proyectos contaban con una conformación de negocio similar a la que plantea esta investigación. Con esto se alude a proyectos que contaban con una oferta variada de ensambles con repertorio de estándares de jazz y que se cobijan bajo una marca. Ambos contaban con presencia en web bien desarrollada -desde el punto de vista gráfico- y de marketing, además de contar con redes sociales propias. Destaca que existía una figura de administrador que se encargaba de agendar las presentaciones, gestionar los contratos y lo músicos eran contratados directamente para cada presentación. Sin embargo, ninguno de estos proyectos provenía de inquietudes musicales propias de los músicos y eran más un resultado de una iniciativa de negocio.

Cabe mencionar que durante el trabajo de campo se identificó que la mayoría de los grupos trabaja en un marco de informalidad desde el punto de vista legal laboral. Se trata de trabajos donde no media ningún tipo de contrato o pago con factura. Esto dificulta, además, la seguridad y garantías sociales para los músicos, ubicándolos en condiciones precarias desde el punto de vista laboral.

Se identificó que el monto mínimo por el que algunos músicos están dispuestos a tocar, en un concierto de dos sets de 40 minutos, de forma regular, en estos lugares (zonas en San José Centro) es de ¿20 mil por músico. Esto podría incluir algún pago en especie como la alimentación. Para presentaciones en zonas como Escazú y Curridabat, se incrementa el pago por traslado. Ciertamente, y como es usual en el medio artístico, lo que cobra un músico varía mucho dependiendo de cuestiones más intangibles como prestigio y popularidad.

Las tarifas, a su vez, varían en función del tipo de evento. La mayor diferencia en precio la hace la regularidad con la que se establezca el contrato. Por ejemplo, si fuese una presentación por semana durante un mes o más, cada concierto costaría menos comparado con un evento puntual un día en particular. También, a más horas de concierto, más alto es el precio; aunque presenta un comportamiento marginal decreciente, no es proporcional el aumento en precio por aumento en horas respecto a la media de concierto.

Otra diferenciación que se hace va en función del tipo de cliente. Los precios para empresas son distintos a los de usuarios directos $y$, además, varían de cara al tipo de evento (bodas, fiestas privadas) y el lugar donde acontezca. 


\section{PRODUCTOS DERIVADOS}

Como se mencionó, se parte de un ensamble de cinco músicos compuesto por dos vientos (saxofón/es, trompeta), guitarra, batería y contrabajo en la base rítmica. Sin embargo, resulta fundamental la creación de derivados que respondan a las distintas características físicas de los lugares como de los distintos presupuestos, principalmente de cara a la demanda desde el punto de vista de los recintos.

Para ello, se conversó con distintos músicos que dieron luz sobre otros tipos de formato y combinaciones instrumentales que pueden acoplarse a las variantes y además son capaces de elaborar repertorios completos de más de tres horas. Cabe resaltar que el jazz tiene un componente alto de improvisación, es difícil determinar puntualmente la duración del repertorio. Por tanto se plantean los siguientes ensambles:

- Dúos:

- Guitarra y contrabajo.

- Guitarra y trompeta o saxofón?.

- Tríos:

- Guitarra, contrabajo y batería.

- Guitarra, contrabajo y trompeta o saxofón.

- Cuarteto: Guitarra, contrabajo, batería y trompeta o saxofón.

En lo que respecta a la guitarra e instrumentos de viento, estos pueden funcionar también como solistas dependiendo del tipo de actividad para lo que se contraten servicios musicales. En cuanto al repertorio, si bien por la naturaleza de esta investigación no se puntualiza en temas concretos, es relevante que el ensamble considere sonidos digeribles y menos comple-

7 En este la lista la palabra saxofón implica tanto para saxo tenor como para saxo alto. Los repertorios se ajustan para ambos instrumentos. jos para un público más general, inclusive piezas que funcionen para el baile de Lindy Hop (estilo de baile).

De igual forma, se debe contar con iconos tanto de compositores como álbumes que han sido claves en la historia del jazz sin que se elimine la dificultad técnica y que sea coherente con la inquietud artística de los involucrados. De hecho, sería recomendable incorporar temas originales que permitan mantener la vena creativa de los involucrados, factor vital en los proyectos artísticos de esta índole.

\section{ESTRATEGIA DE PRECIOS}

Para determinar la estrategia de precios, se tomaron en cuenta distintas variables. Por un lado, la información obtenida sobre la disponibilidad de pago de los recintos que actualmente contratan bandas de jazz o música en vivo en general. Por otro lado, el pago mínimo por evento por el cual están dispuestos a tocar los músicos que fueron entrevistados, según el formato de contratación más típico; es decir, de máximo tres horas (contando el intermedio y los recesos).

Los montos mínimos que se establecieron para presentaciones de dos sets de aproximadamente 40 minutos cada uno fueron:

- San José centro y alrededores:

- ¿40 mil solistas.

- \$30 mil por músico de dúo en adelante.

- Curridabat, Escazú y zonas aledañas a estas:

- ¿50 mil solistas.

- c40 mil por músico de dúo en adelante.

Con base en lo anterior, resulta estratégico establecer los precios mínimos como el equivalente a la tarifa de estrategia de precios de penetración al mercado. Esto porque un precio muy 
bajo o igual al que acepta la mayoría (de 20 mil colones por músico) puede dificultar la diferenciación que se buscaría en función a calidad, repertorio y marca. Por otro lado, si bien los músicos manifestaron que el monto de dinero ideal de recibir por concierto era de $\$ 40$ mil en el caso de San José Centro y alrededores y $\$ 60$ mil en zonas como Escazú y Curridabat, plantear estos precios como punto de partida puede convertirse en una barrera de entrada o limitar a una demanda potencial muy pequeña que limite la posible actividad comercial de un proyecto como este.

Respecto a las presentaciones que se realicen por puerta, se tomó como principal referencia la disponibilidad de pago promedio obtenida como resultado de la información compilada en las encuestas aplicadas para los conciertos de bandas nacionales el pago promedio de los músicos es de $\$ 5.5$ mil y del público en general de $\$ 6$ mil. Por tanto, un precio de entrada ideal, o cover, sería de ¿5 mil por persona. Es importante mencionar que todos los recintos cobran un porcentaje de taquiIla que ronda entre el $10 \%$ y el $30 \%$.

Lograr aforos de aproximadamente cuarenta personas en recintos de modalidad "por puerta" es factible siempre y cuando las presentaciones no sean muy seguidas y roten de lugar para lograr acaparar una mayor diversidad de público con disposición de pago para este tipo de actividades. Si bien se podría pensar en poner un precio menor por presentación para incentivar un mayor volumen de aforo, esto solo funcionaría en recintos donde la capacidad sea mayor a las 100 personas que no es coherente con la realidad de capacidad de los recintos identificados en el trabajo de campo.

\section{IMAGEN, BRANDING Y ESTRATEGIA DE COMU- NICACIÓN}

Para la conceptualización de esta marca, el experto consultado (Mata, Sergio. Comunicación personal, 17 de junio de 2015) considera vital reunir a los músicos con el diseñador, de tal manera que se sientan cómodos con la imagen y gráfica a utilizar. Vincular guiños históricos asociados al repertorio puede resultar interesante para la selección de colores, tipografías y otros elementos de diseño.

Sería fundamental realizar sesiones de fotos y documentación visual y audiovisual que permitan generar contenido en redes sociales y contar con material base para la creación de la web. Además, se diseñó un plan de comunicación basado en redes sociales que permitirá mantener dichos sitios activos y usar la página web más como material de referencia y consulta para los clientes potenciales. El eje de los temas para el plan de comunicación de redes sociales gira en torno a (según su orden de importancia) :

I. Fechas de conciertos y presentaciones.

II. Fechas de conciertos y presentaciones de los miembros en proyectos paralelos.

III. Audios, videos y material fotográfico de las presentaciones.

IV. Referencia a las influencias musicales: compositores, intérpretes, discos y bandas.

Por tanto, se considera fundamental la creación de una web propia como elemento diferenciador y porque da una imagen profesional, utilizando portales fáciles de editar y con capacidad de subir contenido propio principalmente si los recursos limitados impiden contar con servicios informáticos. Esto debe ser acompañado de la presencia en redes y plataformas virtuales que sean relevantes en el género jazz como en la música en general. Además, las redes sociales como herramienta de consolidación y creadores de comunidad y fidelización son indispensables en la actualidad para cualquier proyecto de emprendi- 
miento, más cuando pensamos en la competencia por el tiempo de ocio de las personas.

\section{Resultados de la evaluación financiera}

Para analizar el flujo de caja, primero y conforme a la realidad laboral de los músicos, no se parte de una dedicación exclusiva al proyecto. En segundo lugar, se establecieron tres posibles escenarios en función de la cantidad de presentaciones en un rango hipotético de 6 meses (julio a diciembre de 2015) considerando la opinión de los entrevistados.

- Escenario 1. Pesimista. 6 presentaciones. Aforo de las presentaciones por puerta: 20 personas.

- Escenario 2. Conservador. 9 presentaciones. Aforo de las presentaciones por puerta: 30 personas.

- Escenario 3. Optimista. 12 presentaciones. Aforo de las presentaciones por puerta: 40 personas.
Si bien en diciembre puede haber un aumento en la demanda de este tipo de servicios por las fechas festivas y los períodos de vacaciones, el período de los seis meses se considera de forma integral. Esto quiere decir que, dado que son escenarios hipotéticos, sería muy complicado establecer cuántos conciertos se van a dar en cada mes. De ahí que se considere el período de forma integral y no fraccionado por mes. Además, se establece que en el marco de cada escenario habría dos presentaciones en formato por puerta con el fin de que el ensamble se presente en su alineación completa generando el espacio para la creación artística y manteniendo el incentivo creativo para explorar nuevas composiciones y se mantenga el contrapeso cultural del proyecto.

Tomando en cuenta la cantidad de presentaciones y considerando los conglomerados geográficos, se identificaron cinco zonas donde se podría rotar las presentaciones sin agotar posibilidades de demanda o repetir en lugares que compartan circuitos geográficos cercanos. Se determinó como demanda potencial los establecimientos donde al momento del estudio, existía un presupuesto para contratación de este tipo de servicios, lo que permitió aterrizar

TABLA 3

DISTRIBUCIÓN DE LA DEMANDA POTENCIAL POR ZONAS GEOGRÁFICAS SEGÚN SU MODALIDAD DE CONTRATACIÓN Y DISPOSICIÓN DE PAGO

\begin{tabular}{|c|c|c|c|c|}
\hline Zona & Descripción & Modalidad & Tarifa & $\begin{array}{l}\text { Cantidad } \\
\text { de locales }\end{array}$ \\
\hline 1 & San José Centro y alrededores & Contrato y por puerta & $\$ 30000$ & 11 \\
\hline 2 & Curridabat & Contrato & $\$ 40000$ & 2 \\
\hline 3 & Escazú y Lindora & Contrato & $\zeta 40000$ & 7 \\
\hline 4 & Moravia & Contrato y por puerta & $\measuredangle 30000$ & 1 \\
\hline 5 & San Pedro & Por puerta & N.A. & 2 \\
\hline
\end{tabular}

Fuente: Elaboración propia. 
una demanda potencial más realista evitando una valoración artificial del proyecto.

La base para la creación de los escenarios se planteó a partir de la información en la tabla 3.

Definidos los escenarios, se procedió a aproximar los ingresos potenciales y sus costos asociados para los músicos, puesto en marcha el plan de negocios. Nótese que la proyección se hizo por músico debido a que sería muy difícil estimar los ingresos considerando cada uno de los formatos y sus posibles combinaciones según la cantidad de presentaciones.

Si bien no existe una dedicación exclusiva para el proyecto, se asumieron los costos fijos totales desde el punto de vista laboral de cada músico para esta proyección y los costos variables sí se establecieron en función a los escenarios propuestos. Lo anterior va a tener una implicación importante, dado que se asume el costo total fijo de ser músico profesional per se el flujo de efectivo durante el primer período va a ser siempre negativo.

También, se consideró una inversión inicial de \$2 mil dólares que representa la compra del instrumento. No se contempla una inversión de reposición ya que a nivel profesional los músicos profesionales compran un buen instrumento que en su mayoría utilizan durante toda su vida o la mayor parte de, no solo por cuestiones intangibles como el valor sentimentalismo también características particulares del sonido que emiten dado al cambio de los materiales que van adquiriendo con el cambio del tiempo. Ciertamente esto no descarta compra de más instrumentos o la reposición por pérdida o destrucción del mismo; sin embargo, estos escenarios no se consideran para esta investigación. En la tabla 4, se presentan la estructura de ingresos potenciales por escenario.
De las entrevistas a profundidad a partir de criterio de experto se determinaron los siguientes costos fijos:

- Costo de la seguridad social. Se asumió el 9.34\% mensual establecido por la ley costarricense. Se toma como base salarial el equivalente mensual al salario de un trabajador calificado genérico. El Ministerio de Trabajo establece que dicho salario mínimo corresponde a $\$ 320961,11$. Para la determinación de dicho costo se sumó el acumulado para los seis meses establecidos para el análisis.

- Mantenimiento del instrumento. Si bien dicho costo varía considerablemente en función al instrumento, usos e inclusive gustos y preferencias del músico, como mínimo invierten aproximadamente \$50 mil por semestre en mantenimiento y reparaciones leves. En este rubro se incluye, principalmente, el desgaste por uso y se excluyen reparaciones o arreglos que deriven de situaciones particulares (como caídas, golpes, entre otros) o compras debido a robos o pérdidas. Para la conversión se utilizó el tipo de cambio de venta establecido por el Banco Central de Costa Rica.

- Alquiler de salas de ensayo. Como mínimo un proyecto de esta índole requiere ensayos de forma conjunta una vez al mes, entre dos y tres horas aproximadamente. En momentos de creación musical, usualmente, este tiempo de ensayos se incrementaría; sin embargo, no se considera este tipo de escenario. El costo medio de una sala en esos términos es de \$20 mil. Dicho costo se multiplica por los seis meses de evaluación y se divide entre los cinco miembros, para mantener la misma unidad de medida.

- Impuestos sobre la renta. El Ministerio de Hacienda de Costa Rica aplica un im- 
TABLA 4

ESTRUCTURA DE INGRESOS POR ESCENARIO

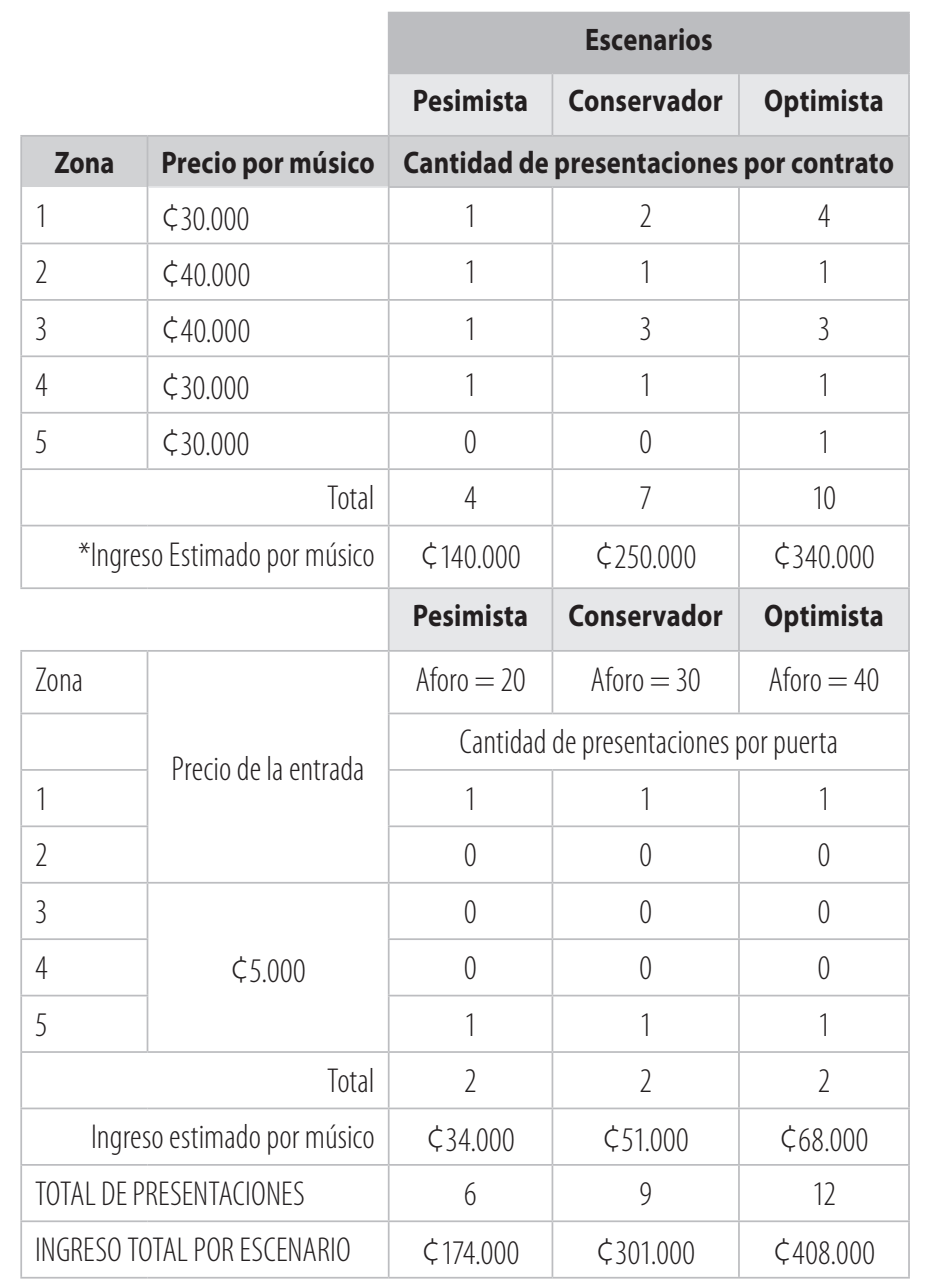

Nota * En este rubro se restó el porcentaje que usualmente cobran los locales por uso del espacio y el equipo de sonido. Se asumió un 15\% al ser la medida promedio que manejan los lugares elegidos durante el proceso de scouting. Nótese además que el pago establecido por músico se diferenció por zona, considerando lo determinado en la propuesta de los escenarios.

Fuente: Elaboración propia.

puesto sobre las utilidades para personas físicas con actividad lucrativa (no asalariados). Según se establece, para el período de 2015, las personas que generen utilidades por debajo de \$3 522000 de quedan exentos de tributar. Por lo que para el caso en cuestión, no afecta el flujo de efectivo propuesto.
TABLA 5

COSTO DE TRANSPORTE POR ZONA GEOGRÁFICA

\begin{tabular}{|c|c|}
\hline Zona & Costo Transporte \\
\hline 1 & $\$ 3000$ \\
\hline 2 & $\$ 8000$ \\
\hline 3 & $\$ 8000$ \\
\hline 4 & $\$ 5000$ \\
\hline$v$ & $\$ 4000$ \\
\hline
\end{tabular}

Fuente: Elaboración propia. 


\begin{tabular}{|c|c|c|c|c|}
\hline \multicolumn{5}{|c|}{$\begin{array}{c}\text { TABLA } 6 \\
\text { ESTRUCTURA DE COSTOS POR ESCENARIO }\end{array}$} \\
\hline & & \multicolumn{3}{|c|}{ Escenarios } \\
\hline & Costos fijos & Pesimista & Conservador & Optimista \\
\hline & Mantenimiento de equipo & $\$ 50.000$ & $\$ 50.000$ & $\$ 50.000$ \\
\hline & Seguro laboral & \29.978 & \29.978 & ¿29.978 \\
\hline & Alquiler sala de ensayo & \24.000 & $\$ 24.000$ & \24.000 \\
\hline & Total & ¿103.978 & \103.978 & ¿103.978 \\
\hline & Costos variables & \multicolumn{3}{|c|}{ Escenarios } \\
\hline Zona & Tansporte & Pesimista & Conservador & Optimista \\
\hline 1 & $\$ 3.000$ & $\$ 3.000$ & $\$ 6.000$ & $\$ 12.000$ \\
\hline 2 & $\$ 8.000$ & $\$ 8.000$ & $\$ 8.000$ & $\$ 8.000$ \\
\hline 3 & $\$ 8.000$ & $\measuredangle 8.000$ & $\$ 24.000$ & $\$ 24.000$ \\
\hline 4 & $\$ 5.000$ & $\measuredangle 5.000$ & $\$ 5.000$ & $\ 5.000$ \\
\hline 5 & $\$ 4.000$ & 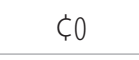 & $\zeta 0$ & $\$ 4.000$ \\
\hline & Total & ¿24.000 & $\$ 43.000$ & $\$ 53.000$ \\
\hline & COSTO TOTAL POR ESCENARIO & $\$ 127.978$ & $\$ 146.978$ & ¿156.978 \\
\hline
\end{tabular}

Fuente: Elaboración propia.

En torno a los costos variables, solo se considera el transporte, ya que es el único costo asociado a cada presentación. De igual forma, se consideraron las zonas establecidas y se asignó un costo estimado de transporte en automóvil público (taxi/Uber) al recinto. De la estructura de costes variables y fijos se obtuvo la siguiente estructura de costos (tabla 5 y 6 ).

Para la proyección del flujo de caja se tomó un horizonte temporal de diez períodos semestrales o, lo que es lo mismo, cinco años, para observar en el tiempo la Tasa Interna de Retorno (TIR), el Valor Actual Neto (VAN) y el Período de Recuperación de la Inversión (PRI) de cada escenario. El detalle de los flujos de caja puede verse en los anexos 1, 2 y 3.

Puede observarse que la depreciación no se incluye como gasto derogable en el flujo. Esto debido al caso particular del tratamiento de los instrumentos, los cuales no se deprecian como los activos normales como, por ejemplo, un carro o una computadora.

Para el cálculo del VAN se utilizó la tasa de interés promedio del primer semestre del 2015 del Banco Central de bancos privados para préstamos en moneda nacional para servicios. Se obtuvo un $15.88 \%$ de interés, esta tasa fue la más cercana a simular el costo de oportunidad para el caso de un proyecto artístico. En el caso del PRI, para tomar en cuenta el valor del dinero en el tiempo, se obtuvo la utilidad descontada, utilizando la misma tasa de interés del cálculo del VAN.

Además, se utilizó el promedio del tipo de cambio publicado por el Banco Central entre el 17 de julio de 2015 al 15 de agosto de 2015 y se tuvo un valor 
de $\$ 540.75$ por dólar. La tasa de 5\% semestral de incremento en precios se empleó para mostrar el aumento de los ingresos y los gastos en el tiempo. En la tabla 7 se resumen los resultados principales de la evaluación financiera.

Nótese que, para el caso del escenario conservador, la Tasa Interna de Retorno es positiva; mientras que, para el escenario optimista respecto a esta, implica un aumento de más de 100\% en la TIR. El Período de Retorno de la In-

\section{TABLA 7}

RESULTADOS PRINCIPALES DE LA EVALUACIÓN FINANCIERA

\begin{tabular}{|c|c|c|c|}
\hline Escenario & TIR (\%) & VAN (\$) & PRI (períodos) \\
\hline Pesimista & -9 & -1302.74 & 10 \\
\hline Conservador & 11 & -309.77 & 10 \\
\hline Optimista & 24 & 582.07 & 7 \\
\hline
\end{tabular}

Fuente: Elaboración propia.

versión (PRI) se mantiene igual hasta el escenario optimista. EI VAN, en cambio, sí aumenta de forma considerable dependiendo de cada escenario. Las tres medidas en su forma evidencian el incremento en el valor que puede generar un plan de negocio inclusive para un proyecto de naturaleza tan compleja y diversa como este.

\section{CONCLUSIONES}

Esta pesquisa mostró resultados esclarecedores. Por un lado, las personas que asisten a eventos de jazz, en su mayoría, conocen el género y, de una u otra forma, han estado inmersos en la música. Una minoría accede a dichos eventos por casualidad y de forma irregular. Es evidente que hay un factor cultural muy importante que, en cierta medida, puede estar conteniendo o condicionando la inclusión del jazz así como su desarrollo en la escena artística-musical. Debe recordarse que, en Costa Rica, la exposición al jazz en el entorno es mínima; desde los medios de comunicación o en la parte de formación educativa. Sin embargo, en la actualidad gracias a la tecnología y al internet conocer y acceder a este tipo de géneros es más sencillo por lo que se puede independizar el consumo de las estructuras del entorno.

Durante el momento de realizar esta investigación, ninguno de los centros educativos principales que desarrollan músicos (UCR, UNA) contaba con programas de jazz o, en general, de otros géneros aparte de la música clásica y popular. Lo anterior es relevante para considerar políticas públicas que realmente permitan profesionalizar aún más a este gremio y trabajar en la paridad de género.

Es una minoría la que logra acceder a una educación de postgrado en áreas de la música "desconocidas" y muchos poseen preparación netamente empírica o fuera de los circuitos oficiales de formación. Lo anterior, aunado a un desconocimiento generalizado de la población, impide el desarrollo de este sector no solo hablando del jazz, sino considerando también otros géneros musicales que actualmente existen y se tocan en Costa Rica. Parece evidente que vivir de la música aún es muy complicado en este país y no se puede hablar de una industria musical más que en un nivel incipiente. Por tanto, el Estado o al menos las instituciones públicas involucradas deberían actualizar los programas musicales, mejorar la educación en la música en niveles básicos de educación pública y re-direccionar recursos económicos tal y como se hizo durante los años setentas por la música clásica. Si bien existen locales comerciales que ven la música en vivo como un servicio adicional para su clientela, la mayoría posee un presupuesto muy pequeño para ello y en general no se considera el factor de profesionalización del músico y su nivel técnico, así como la calidad de la música y repertorio interpretado. 
Sería clave extender este tipo de ofertas culturales a zonas fuera de San José, poniendo el acento en Heredia y Alajuela, que cuentan con demandas insatisfechas. Sin embargo, desde un punto de vista de políticas públicas, sería interesante que desde el músculo público se programaran conciertos en espacios públicos en zonas rurales, costeras y de bajos ingresos que permitan democratizar el acceso a este tipo de iniciativas. De igual forma, proyectos como este pueden encontrar un mercado potencial relacionado con las zonas turísticas de estos sectores geográficos que presentan altas concentraciones de hoteles, restaurantes y bares.

Buscar alianzas con instituciones públicas culturales o centros culturales privados también pueden ayudar a la Estrategia de penetración y es una forma de fidelización de usuarios. Además, es una forma de crear un tipo de presentaciones que pueden ser más didácticas y que permitan un acceso a grupos de personas que no están familiarizados con este tipo de proyectos y música en general.

En el caso de los competidores, resulta claro que es un mercado que se rige en un marco de informalidad. Aunado a esto, no existe ninguna agrupación que agremie a estos profesionales. ACAM, por su lado se limita a la gestión de derechos de autor pero no tiene impacto en la precarización de las garantías laborales de las y los músicos. Los contratos en general son verbales y en muy pocas ocasiones incluso no median facturas o documentación oficial de ningún tipo.

Una forma de diversificar y mejorar la sostenibilidad financiera de un proyecto de esta naturaleza es introducirse en el mercado de eventos privados, tales como bodas, fiestas de empresas, aniversarios, entre otros. Este es un mercado que en general utiliza este tipo de servicios de forma constante y posee una disposición de pago en general más alta que un local comercial.
Es de vital importancia la puesta en marcha de los otros formatos derivados de un proyecto concreto para que puedan adaptarse a las distintas condiciones de los demandantes tanto en cuestiones de espacio como presupuestarias. Incorporar estos formatos permite ampliar las posibilidades de contratos con los locales comerciales.

Un desarrollo de marca permite la diferenciación y le da un carácter formal de proyecto empresarial sin sacrificar el componente artístico. El uso de las redes sociales de forma constante y permanente es vital para mantener contacto directo con las personas que actualmente escuchan jazz, crear comunidad, fidelizar y también para captar nuevos públicos.

La creación de escenarios hipotéticos permitió evidenciar que, incluso en un escenario pesimista, el pensar un proyecto como este como un emprendimiento permite mejorar la rentabilidad de mismo en el tiempo sin deslegitimar el componente artístico. Además, conocer la demanda potencial y los competidores proporcionó material para generar estrategias más eficientes que aumenten la rentabilidad del proyecto. Lograr contratos en lugares distintos, pero mejor pagados, con una carga de trabajo de una presentación por semana, partiendo de la diferenciación por zonas, sería el escenario ideal de un proyecto como este.

El estado incipiente de la industria musical en Costa Rica viene siendo resultado del atraso y ausencia de proyectos o políticas públicas que articules los esfuerzo, al igual que el estancamiento que tienen los programas universitarios en las carreras de música, los cuales no corresponden a la realidad del mundo actual. De ahí la relevancia de proyectos como este que además se gesten considerando factores de sostenibilidad para que no se queden en iniciativas estériles o que sean proyectos de muy corta duración. 
De igual forma, es vital que desde la formación básica educativa se mejoren los contenidos de los programas de arte y música. De manera tal que se logre crear un acervo más potente en materia cultural y permita la creación orgánica de públicos en arte y cultura, concordando con las nuevas teorías de desarrollo humano mencionadas al inicio de esta pesquisa.

Finalmente, es vital que exista algún organismo que permita articular a los músicos y, con ello, se logren mejores condiciones a nivel académico como en sus condiciones laborales. De este modo, se logra salir del marco de la clandestinidad y precarización laboral, además de profesionalizar el medio que ya de por sí cuenta con músicos profesionales de alto nivel y evitar la fuga de cerebros.

\section{REFERENCIAS}

ACAM, Costa Rica. (2012). Qué es ACAM y cuál es su labor. Recuperado de http://www.acam.cr/quees-acam-y-cual-es-su-labor/

Alfaro, G. (2003). Estudio de factibilidad financiera para el establecimiento de una franquicia Musmanni en la provincia de Alajuela. (Tesis de mestría). Universidad de Costa Rica, San José, Costa Rica.

Amaya, C. (Enero de 2010).Un reto para la mercadotecnia en el arte de la fijación de precios. Recuperado de: http://cristinaamaya.com/2010/01/un-retopara-la-mercadotecnia-en-el-arte-la-fijacion-deprecios/

American Marketing Association. (2014). www.ama. org. Recuperado de https://www.ama.org/resources/Pages/Dictionary.aspx?dLetter $=$ B

Araya Córdoba, M. (2006). Viabilidad financiera para la modernización y decisión de inversión del Restaurante Llano Grande. (Tesis de maestría) Universidad de Costa Rica, Guanacaste, Costa Rica.

Bodie, Z., \& Merton, R. (2003). Finanzas. México: Pearson.

Casani, F., Rodríguez, J., Morcillo, P., Martín, C., Minguela, B., Sánchez, F., ... Carsi, R. (2010). Indus- trias de la Creatividad. Recuperado de: http:// www.eoi.es/blogs/20creativa/files/2010/08/ NUEVA_ECONOM\%C3\%8DA_2020_EOI_Industrias_Creatividad.pdf

Cifuentes, J. C. (1995). El Gran Jazz. Volumen II: La era del Swing y los grandes solistas clásicos. Madrid, España. Ediciones del Prado, S.A.

Fernández, S. (2010). Los proyectos de inversión. Evaluación financiera. (Segunda edición ed.). Cartago, Costa Rica: Editorial Tecnológica de Costa Rica.

Ferrel, O. C., \& Hartline, M. (2012). Estrategia de marketing. México D.F.: Cengage Learning, Inc.

Ferrel, O., \& Hartline, M. (2012). Estrategia de marketing. México D.F.: CENGAGE Learning.

Gonzáles, A. (2012). Capítulo 1: La problemática en torno a los paradigmas de investigación. Recuperado de http://es.scribd.com/doc/2628740/Cap-1-paradigmas-actual

Hernández, R., Fernández, C., \& Baptista, P. (2006). Metodología de la investigación. (Cuarta Edición ed.). México D.F:: McGraw-Hill Interamericana.

Jaime Eslava, J. (2009). Pricing: Nuevas estrategias de precios (2a. ed.). Madrid: ESIC Editorial.

Koenes, A. (1994). El plan de negocios. Guías de gestión de la pequeña empresa. Madrid, España: Ediciones Diaz de Santos.

Kotler, P., \& Amstrong, G. (2003). Fundamentos de Marketing (Sexta edición ed.). México DF: Pearson Educación.

Miranda, J. J. (2005). Gestión de proyectos: identificación, formulación, evaluación financiera, económica, social, ambiental ( $5^{\circ}$ ed.). Bogotá, Colombia: MM.

Naveros, J. A., \& Cabrerizo, M. D. (2009). Plan de Negocio. España: Publicaciones Vértice S. L.

Núñez, G. (Enero-Febrero de 2009). Es necesaria una visión académica del jazz: Semblanza del pianista y compositor costarricense Luis Monge. La Retreta, II(1).

OUGAM. (2014). La Gran Área Metropolitana. Recuperado de: http://ougam.ucr.ac.cr/index.php/la-gam 
PMBOK, G. D. (2004). Guía de los fundamentos de la dirección de proyectos. Pennsylvania, Estados Unidos: Project Management Institute.

Pérez, M. (2015). Propuesta de un plan de negocio enfocado en el aumento de valor del proyecto de jazz costarricense Studio Project Quintet. (Tesis de maestría). Universidad Estatal a Distancia, San José, Costa Rica.

Porter, M. (1997). Estrategia Competitiva. C.V. México: Editorial Continental, S.A.

Rolf, J. (2007). Jazz. La historia completa. Barcelona: Ediciones Robinbook.

Sáez, G. (2012). Para que tractores sin violines (2a ed.). San José, Costa Rica: Master Litho S. A.

Sapag, N. (2011). Proyectos de inversión. Formulación y evaluación. (2a. ed.). Santiago, Chile: Pearson.

Scofield, J. (2007). Prólogo. Jazz, la historia completa. En J. Rolf, Jazz. La historia completa. (pp. 10-11). Barcelona: Ediciones Robinbook.
Sequeira, E. (19 de Mayo de 2015). Escena del jazz en Costa Rica. (M. Pérez, Entrevistador)

Torreblanca, F. (25 de Marzo de 2014). Cómo diferenciar competidores directos e indirectos Recuperado de: http://franciscotorreblanca.es/diferenciar-competidores-directos-e-indirectos/

Towse, R. (2010). A textbook of cultural economics. New York: Cambridge University Press.

UNESCO. (2011). Culture and development. Recuperado de: http://www.unesco.org/new/fileadmin/ MULTIMEDIA/HQ/CLT/pdf/Conv2005_CDindicators_SG-ReportC+D_en.pdf

UNICEF. (2012). Invertir en cultura es invertir en la gente. Recuperado de http://www.unicef.org/costarica/media_22876.html

Recibido: 16 de mayo de 2017 Aceptado: 23 de enero de 2018 


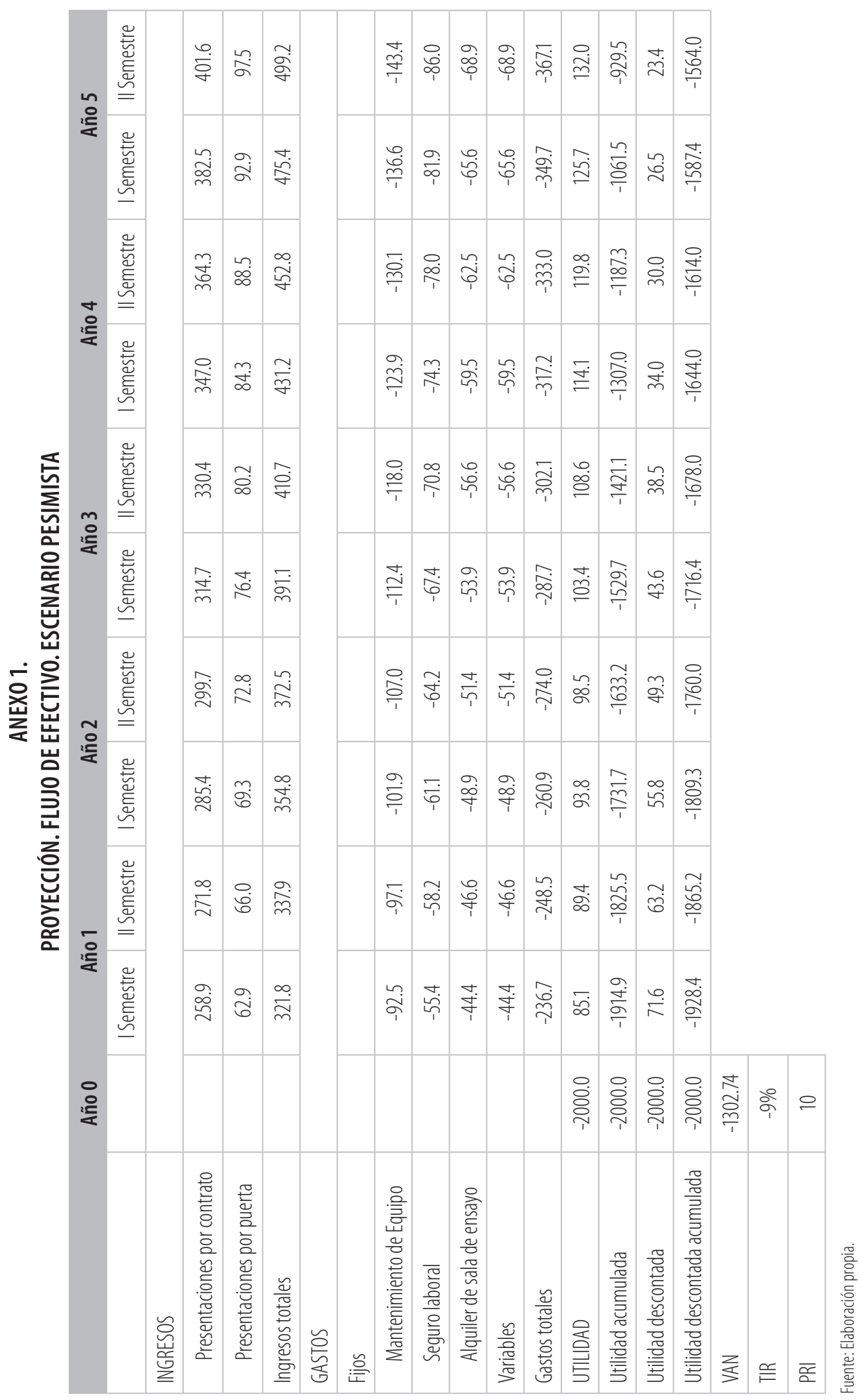




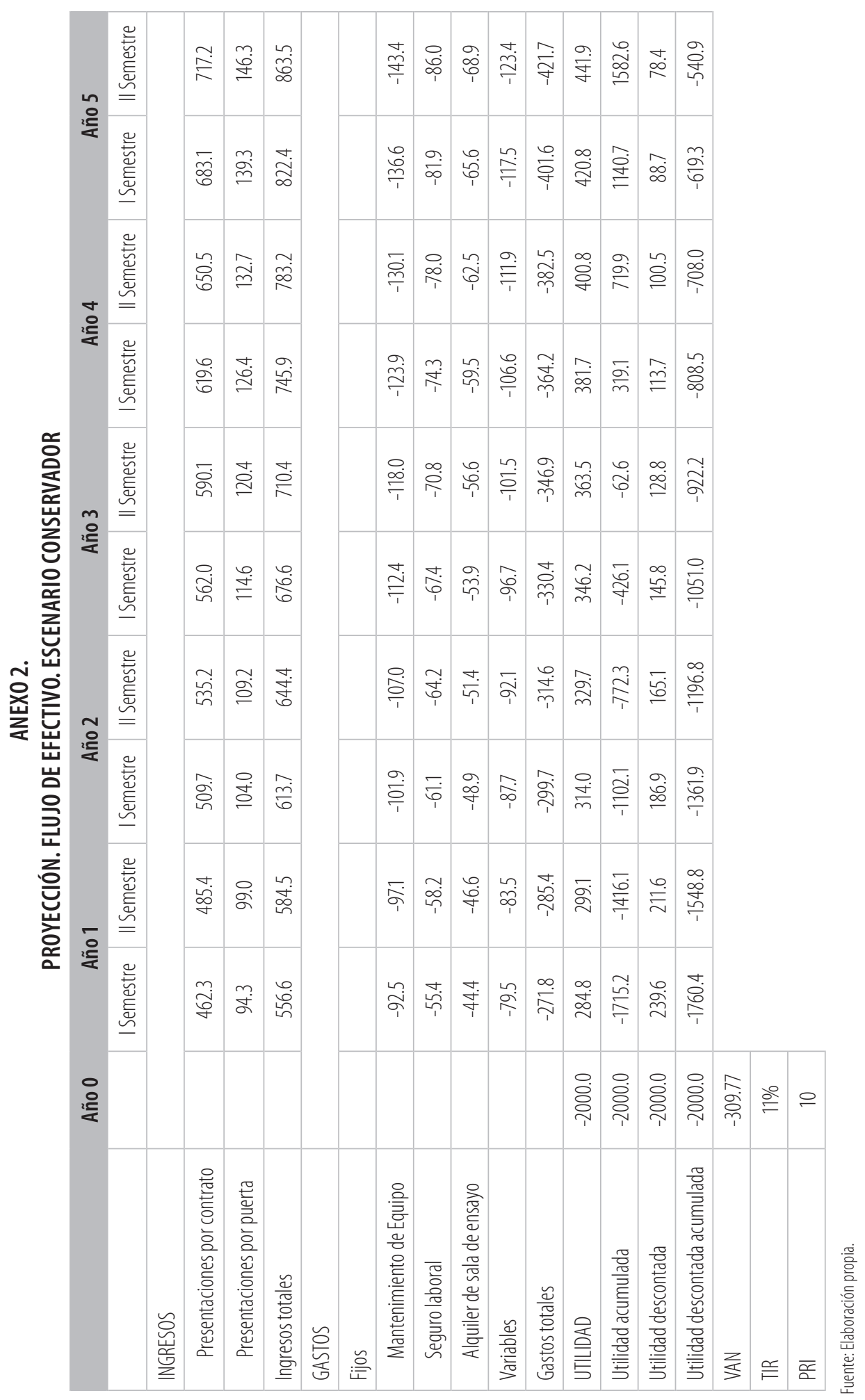




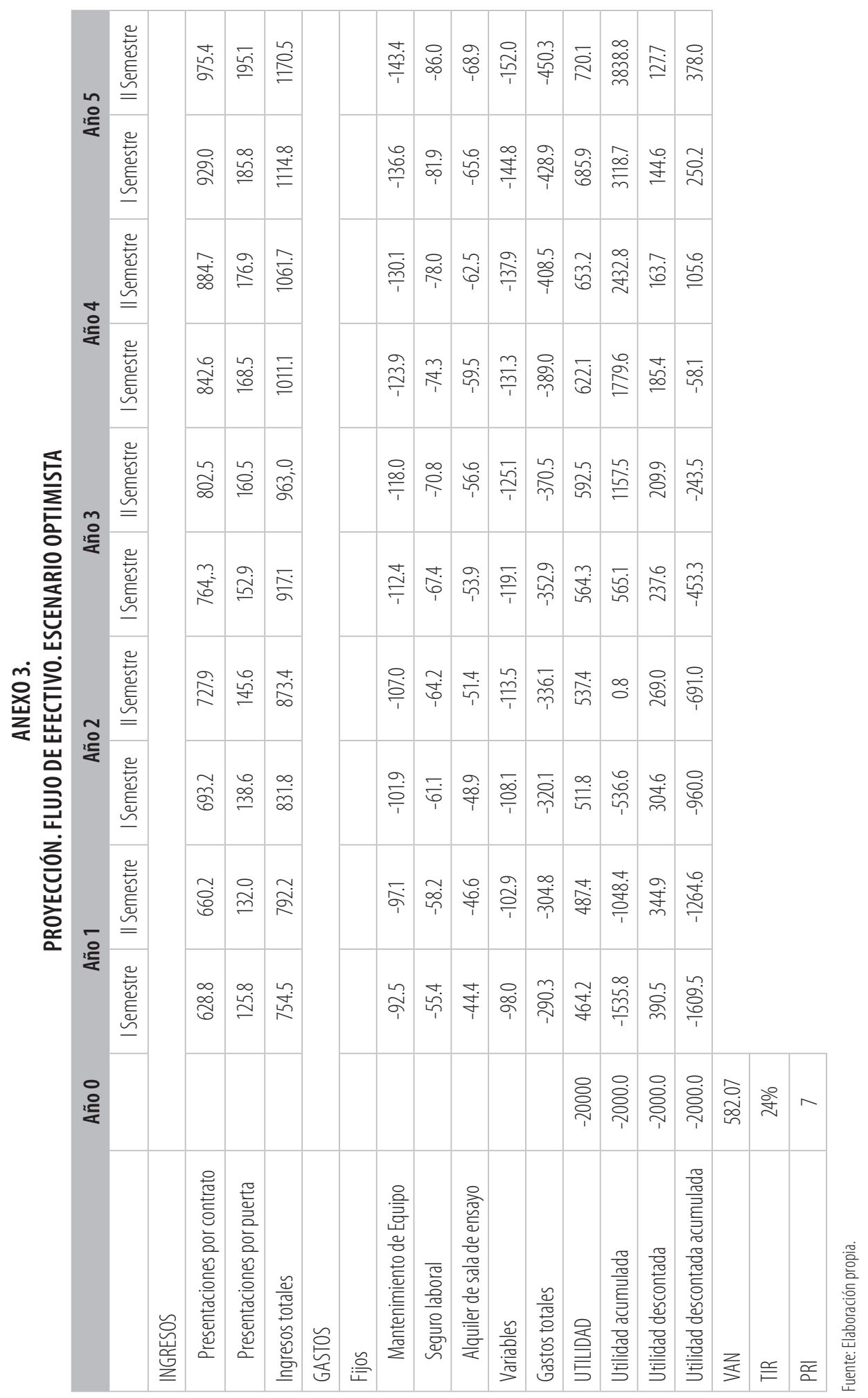

